\title{
Lenguajes, retóricas y repertorios de egresados de un colegio público "de elite"
}

Alicia Méndez *

http://dx.doi.org/10.1590/0103-7307201507706

\section{Resumen}

El objetivo de este artículo es analizar, a partir de un ejercicio de antropología reflexiva, cómo ciertos lenguajes, retóricas y repertorios pueden aludir a la idea de comunidad, a propósito de egresados de un colegio público de elite, paradigmático en la *Universidad de Buenos Aires (UBA), Buenos Aires, Argentina. aliciamzv@yahoo.com vida intelectual y política argentina, el Nacional de Buenos Aires (CNBA). Se apunta asimismo a documentar esas mismas prácticas, movilizadas en situaciones concretas por los graduados para disputar determinados recursos cruciales en y para los colectivos (en este caso, segregativos) de los que forman parte. Por último, y a propósito de un incidente de campo, me interesa indagar de qué otros modos se pueden pensar las acciones de una elite, que no necesariamente son instrumentales, y cuyo sentido implica a la figura del investigador social como co-partícipe de la producción de la evidencia.

Palabras clave: Colegio Nacional, Buenos Aires, elite, comunidad, retórica, antropología reflexiva 


\title{
Linguistic and rhetoric repertoires in the collective life of elite high school alumni
}

\begin{abstract}
This article analyzes, from the point of view of reflexive anthropology, how certain linguistic and rhetoric repertoires used by alumni of the elite Buenos Aires National High School may allude to the idea of community. By exploring the situations in which these reportoires are activated, we show how they can act as an important resource in the struggle to obtain professional and political privileges. Finally, in connection with a "field incident", we inquiry about the co-participation of the social researcher in the production of evidence.
\end{abstract}

Keywords: National high school, Buenos Aires, elite, community, reflexive anthropology 
1. El CNBA fue fundado en el año 1863 por el entonces presidente de la Nación, Bartolomé Mitre. A lo largo de su historia centenaria se constituyó como un referente paradigmático en el proceso de formación de jóvenes en la Argentina, desde la Generación del 80 a los Liberales Reformistas ${ }^{1}$; desde Montoneros ${ }^{2}$ a La Cámpora ${ }^{3}$. En ese colegio se formaron no solo tres presidentes y dos Premios Nobel sino también quienes ocuparon y ocupan e incluso crearon espacios de la vida nacional, así como quienes han definido y definen en buena medida los criterios con que se rige la actividad académica local. Esos notorios exponentes de la alta administración pública y privada, de las profesiones liberales, las ciencias y las artes constituyen una porción del alumnado que con sus logros profesionales ha contribuido a mantener su continuidad en el tiempo.

Esa institución, cuya relevancia es reconocida por personas que pertenecen a sectores muchas veces enfrentados en términos políticos, está situada en la zona de Buenos Aires llamada "La Manzana de las Luces"; el centro histórico de la ciudad, donde se encuentran los edificios y espacios que funcionan como símbolos máximos de la autoridad política del Estado, de la potestad divina, del poder financiero y de constitución de la identidad nacional.

Se trata de una institución universitaria que utiliza un muy exigente y fiscalizado examen de ingreso. Este rasgo resulta excepcional dado que, exceptuando algunos colegios de su tipo, predomina en el contexto nacional un punto de vista favorable a la apertura general de los sistemas educativos y la abolición de los exámenes de ingreso en la escuela media (Del Piero, 2013; Southwell, 2011; Tiramonti, 2004).

Se comprende mejor la ubicación del CNBA dentro del sistema local de formación de elites, si se parte de la idea de que existen configuraciones institucionales diferenciales, ya sea para la atención de distintos públicos selectos, ya sea para la formación de elites "meritocráticas". Según la bibliografía especializada, hay escuelas secundarias que "educan para la competencia", escuelas que "educan para la conservación y en los valores cristianos" y escuelas que educan para la "distinción intelectual" (Ziegler, 2004). Las dos primeras se refieren a instituciones privadas y la tercera, a colegios universitarios, entre los cuales

1. Un colectivo compuesto en gran medida por egresados del Colegio que intervino en la conformación de políticas sociales poniendo en uso ciertos principios que forman parte de las virtudes republicanas (Zimmermann, 1995) 2. Montoneros" fue una agrupación político militar autoadscripta al Peronismo, fundada en 1970, entre otros, por los ex alumnos Mario Eduardo Firmenich, Carlos Gustavo Ramus, Fernando Abal Medina. Contó con el apoyo del peronismo hasta 1974 .

3. La Cámpora es una agrupación juvenil fundada por Máximo Kirchner, hijo de la pareja presidencial en el poder desde 2003. Entre sus principales referentes son egresados del CNBA el actual ministro de Economía, la embajadora en Estados Unidos, así como legisladores y otros miembros muy visibles del funcionariado estatal. 
el Colegio Nacional de Buenos Aires se distingue por su tradicionalidad y por la notoriedad pasada y presente de algunos de sus egresados.

De la instancia del ingreso y de las rigurosas condiciones de permanencia que rigen en la institución, resulta un alumnado altamente diferenciado que es producto de un reclutamiento no ceñido a una pauta residencial fija, por lo que su población ha sido, desde su fundación, socialmente heterogénea4. Ese patrón de reclutamiento relativamente abierto en cuanto a la procedencia de las familias respecto de los otros dos tipos de instituciones privadas de elite, es también un rasgo diferencial del CNBA.

Otro rasgo singular del centenario colegio es que el acceso de sus egresados a lugares de primer nivel en la vida institucional, académica y cultural del país no alcanza a ser explicado ni por la posesiones; ni por la pertenencia a un estrato social particular; ni por la antigüedad o la tradicionalidad de sus familias. Según la literatura argentina que se interesó tanto en el reclutamiento y formación de elites de entre fines del siglo XIX y mediados del XX, como a posteriori de 2001, esos han sido los recursos movilizados para acceder a posiciones bien remuneradas o prestigiosas, salvo excepciones, recursos siempre provistos por la familia. Ese punto de vista reproduce el de los actores, para quienes las distintas elites están formadas “por familias”.

Los egresados del CNBA, en cambio, personas que contaron con recursos familiares desiguales, relataron su ingreso y permanencia en el Colegio como un inusitado reto personal; son quienes, pese al apoyo familiar, aprendieron desde el ingreso a "gerenciarse solas". De ese modo, las familias, en tanto objeto de indagación, se desplazan del centro de la escena. Una elite como la que se asocia al CNBA está formada básicamente, entonces, por individuos, y allí entra el problema de la meritocracia y el de los modos "no tradicionales”, o al menos no codificados por la sociología, como el que examinaremos en este trabajo, según los cuales los grupos de individuos ligados

4. En el libro (Méndez, 2013) se presenta un perfil sociodemográfico realizado en base a datos del archivo del Colegio tratados a partir de un método sistemático y al azar para la conformación de muestras tomadas en dos años no consecutivos cada dos décadas. La metodología implicó a su vez la realización de más de 50 entrevistas en profundidad; la revisión de material autobiográfico y otras fuentes documentales; y un estudio prosopográfico de egresados que accedieron a posiciones de gran visibilidad en la vida política nacional. Asimismo, se implementó un estudio comparativo con un caso paradigmático de formación de elites estatales, el francés. a ella logran su continuidad a lo largo del tiempo.

El examen de ingreso ha sido desde 1957, es decir, desde que existe el examen obligatorio para todos, el primer momento de un proceso de socialización en el que se ha introducido a los alumnos en un sistema de valores nuevo, en el que el esfuerzo individual ha sido el centro de referencia. Puede pensarse a su vez que allí se ha venido jugando la identidad de los alumnos; la representa- 
ción que ellos comenzaron a hacerse de su distinción en tanto ingresantes a un colegio muy renombrado. Es posible, por su parte, describir esa dinámica como un doble mecanismo: por un lado, el reconocimiento mutuo entre quienes pasaron por esa misma experiencia formativa y, por el otro, la diferenciación de quienes no: la familia (si no eran "ex CNBA"), los amigos del barrio, los que desaprobaron la instancia de examen; la sociedad en general. La desigualdad que se iba estableciendo entre los individuos que cursaron su secundario en el CNBA y el resto de la sociedad no era algo dado de una vez y para siempre, sino que ha supuesto y supone un trabajo constante de producción por parte de esos egresados, de manera individual y colectiva.

Bruno Latour (2008), en su libro Reensamblar lo social, ha escrito que los grupos no son "cosas silenciosas" (p.53), tampoco entidades constituidas de una vez y para siempre, sino un producto provisorio, de voces contradictorias, y su delineado y persistencia responde a un trabajo continuo de producción individual y colectiva. En este artículo analizaremos otras instancias del largo proceso de socialización como ex alumnos en las que se refuerza colectivamente ese sentimiento de pertenencia y, como contracara, esa diferencia: modos que, entendemos, pueden apuntar a garantizar la persistencia de la excepcionalidad de esos egresados, excepcionalidad que es la de la institución.

Hasta aquí, rasgos que, salvo excepciones muy puntuales en la historia del CNBA, podría decirse que definen en general a los egresados de la institución. La exposición de las variaciones y las persistencias a lo largo de esos 151 años demandaría demasiado espacio y fueron desarrolladas en otro lugar (Méndez, 2013). Aunque algunos aspectos puedan ser compartidos por egresados de otros momentos de la institución, nos referiremos de aquí en más a quienes egresaron en los años post Malvinas 5 , cuando ocurrió el episodio que analizaremos en este artículo.

Según los relatos registrados, la socialización en el CNBA fue dando cabida a un modo de ver a los otros, de definir el propio estilo y los lugares de sociabilidad de acuerdo no al poder adquisitivo ni a los gustos propios de un grupo etario particular, sino a la interiorización de una pauta externa como es la del control del tiempo, el rigor intelectual, un sistema disciplinario estricto y un modo de funcionamiento institucional organizado en base a reglas no negociables. Los colegios privados suelen ser menos estrictos en este punto. No

5. "La Guerra de Malvinas" fue un conflicto armado entre Argentina y Gran Bretaña por los archipiélagos sudatlánticos ocurrido entre el 2 de abril y el 14 de junio de 1982 en el que la Argentina ocupó, con fines de recuperación, estos territorios invadidos por Gran Bretaña en 1833. Si no la única, fue esta una de las muy pocas coyunturas de su historia moderna que dio lugar a un amplio consenso cívico militar basado en la pertenencia nacional (Guber, 2004). 
parece menos decisiva la transmisión de un relato, vía las autoridades, los profesores, o bien, algunas familias con varias generaciones de ex alumnos, que los incluyó en una tradición ilustrada y laica, en la que se valora el ascenso social por la vía de las inversiones simbólicas ${ }^{6}$. Tampoco parece tener menos relevancia la construcción de un mandato escolar dirigido a ocupar lugares relevantes dentro del concierto de voces de la Nación, más allá del modo en que en la vida adulta cada uno logre dialogar en ese ideal.

Existen repertorios puntuales que persisten en estos egresados que aluden (y puede decirse que trabajan para reforzar) el tema de la preeminencia del CNBA respecto de otras instituciones locales. Algunos egresados se refirieron, durante las entrevistas, al hecho de que el gesto de nombrarse, por ejemplo, como “"El' Colegio" y ser "el centro de la cultura argentina", es algo que se lo dijeron los profesores y autoridades desde el primer momento. Por eso mismo, como contó un egresado de alrededor de 45 años, comentar en una charla casual con cualquier argentino mínimamente informado que se es ex alumno de esa institución equivale a "sacar el ancho de espadas": la carta más alta en el Truco, un juego de naipes difundido en América del Sur y muy popular en Argentina.

En los "haber ido al" o "ser egresado del Colegio" "a secas" - o simplemente "ser del" Colegio - , repetidos hasta el cansancio por sus alumnos y egresados de todas las generaciones, tanto en la contracción “al” ( $\mathrm{a}+\mathrm{el}$ ) como en la "del” (de + el) obligatoria para la gramática española, persiste el artículo “el”. “El”, aquí, es una sinécdoque de “El colegio de la patria”, “El mejor colegio del país”, “El colegio universitario”, el único colegio que reúne todas las condiciones, el mejor y el peor.

Un egresado comparaba al CNBA con los otros dos colegios universitarios porteños: el Pellegrini y el ILSE7 ${ }^{7}$ instituciones también centenarias ${ }^{8}$, utilizando una suerte de arenga: "Los del Pellegrini son una escuela; los del ILSE son un instituto; colegio,

6. Relato que persiste pese a las fuertes impugnaciones sufridas a lo largo de su historia, en particular, en la década de 1970.

7. Se trata de la Escuela Superior de Comercio Carlos Pellegrini y del Instituto Libre de Segunda Enseñanza.

8. El Pellegrini es de orientación comercial y el ILSE es humanista, como el CNBA, pero mixto: depende de la Universidad de Buenos Aires, una universidad pública y gratuita, pero cobra una cuota moderada (muy menor a la de un colegio privado bien conceptuado de Capital Federal).
'El Colegio', las dos veces con mayúscula, somos nosotros". También en esa retórica se ligan términos que no suelen ir juntos: la educación en un colegio estatal fundado en el siglo XIX y los grupos influyentes de la sociedad porteña.

Los modos de relación entre egresados del CNBA a lo largo de su vida también resultan excepcionales, si se los compara con los egresados de 
otros secundarios porteños. Algunos ex alumnos que no se conocieron durante el secundario, se “descubren”, con los años en reuniones de ex alumnos. En esos encuentros a veces se reafirman lazos y sentimientos de pertenencia a la institución, y en otros, se los inventa. La sociabilidad se implementa en instancias informales, a través de los años, pero también en reuniones organizadas por ex alumnos de una misma división, o, en fechas clave, por el mismo Colegio. Esas últimas reuniones aparecen como espacios en los se realiza un control estricto sobre la trayectoria profesional de los antiguos compañeros. La verificación tiene por objeto la concreción de "carreras buenas y rápidas"; y de viajes para hacer posgrados en el exterior, que, inscriptos en un proceso de "internacionalización de la ciencia” proveen nuevas instancias de sociabilidad y de tendido de redes que resultan compensatorios ante la depreciación de los títulos otorgados por una universidad pública cada vez más masiva.

Se trata de encuentros en los que cada uno compara la posición propia con la de los otros con la esperanza de salir airoso del cotejo, y a la vez se constata que los colegas sean lo suficientemente exitosos como para que valga la pena seguir considerándose parte de esa totalidad y de ese juego. Son maneras de construir relaciones sociales y prestigio para sí y para los demás egresados: el "éxito" o la notabilidad alcanzados en forma individual, en este contexto se capitaliza en forma colectiva y viceversa.

También ocurre que ex alumnos acuden a profesionales (como médicos o abogados) que tienen como única referencia ser "ex CNBA" y a quienes no conocen; o comienzan a beneficiar, en el ambiente laboral, a subordinados una vez que se enteran de que son egresados de "el Histórico"; en ciertas ocasiones los incluyen en una primera selección pre-ocupacional entre aspirantes igualmente desconocidos. Puede decirse que se perciben como parte de redes profesionales, políticas y de amistad a una escala relativamente amplia, formadas en base a la "confianza" que les despiertan a egresados del CNBA personas nunca vistas antes en las que descubren ese “origen” común, con las cuales se piensan como "conectados" a lo largo de sus vidas, ayudados o impulsados por ellos, a veces en una dinámica de alcance mayor que puede pensarse que termina contribuyendo a “armar” y a preservar al grupo.

2. Durante el trabajo en el terreno, cuatro egresados se vieron en la circunstancia de explicar una actitud por lo menos curiosa que ellos y sus compañeros sostuvieron hacia el fin de la cursada de su secundario, de la que supe por primera vez por parte de alguien de mucha confianza, también "ex CNBA". 
Entre otras actitudes, también llamó mi atención un gesto, aparentemente no del todo desconectado del anterior, por el que uno de esos egresados, historiador de profesión, tras encontrarse casualmente, poco tiempo después de que yo lo conociese, con un periodista y antiguo compañero de secundario, le contó a este último sobre mi investigación y lo instó a contactarse conmigo para que lo entrevistase. Se trataba de dos militantes, muy renombrados, de la política estudiantil de ese momento del Colegio. Yo había hablado ya varias veces con este periodista, teníamos cierta confianza y fue él quien me reveló este encuentro. El historiador, por su parte, me sugirió algunas lecturas que podrían servirme para mi tesis de doctorado sobre la formación de elites en el CNBA. Otros egresados hicieron lo propio.

Quisiera evaluar hasta qué punto sendos gestos, que deben leerse teniendo en cuenta la "conexión" que guardan entre sí los actores, una conexión que como se sugirió, excede esa relación entre dos egresados, permiten pensar en la idea de comunidad a propósito de los egresados del CNBA, tal como la definieron algunos autores clásicos y contemporáneos de la Sociología; y hasta qué punto tensan las de otros. En ese sentido, me resulta estimulante pensar posibles respuestas a una pregunta formulada por Edmund Leach y retomada recientemente por Gabriel Noel (2014): ¿cuáles son los lenguajes, las retóricas, los repertorios socialmente disponibles que los actores sociales movilizan en situaciones concretas para disputar determinados recursos cruciales en y para los colectivos (en este caso, segregativos) de los cuales forman parte, (a lo que agregaría): como una manera de velar por su continuidad? Por último, y a propósito del modo en que las versiones sobre ese episodio en principio tan curioso me fueron llegando durante el proceso del trabajo de campo, me interesa indagar de qué otra forma se pueden pensar las acciones de un colectivo que desarrolla conductas orientadas a su diferenciación; modos no necesariamente instrumentales, por un lado, y por el otro, que tomen en cuenta, por ejemplo, la figura del investigador social como co-partícipe de la producción de la evidencia.

A propósito de la cuestión central a examinar, describiré aquel episodio que involucró de manera directa a quienes estaban próximos a egresar del CNBA y que surgió como respuesta a una iniciativa político educativa que modificó su status en tanto alumnos de un colegio universitario y, por lo mismo, puso en cuestión el status del colegio en tanto institución de elite: la pérdida de

9. La investigación aludida se llevó a cabo entre fines de 2004 y mediados de 2010. la prerrogativa de ingresar en forma directa a la universidad. 
Los cuatro hombres que me hablaron de aquello no eran al momento de tener un intercambio conmigo necesariamente amigos, pero sí se recordaban y se referían entre sí, como permite advertir la referencia al breve contacto que sostuvieron el periodista y el historiador.

3. Luego de Malvinas, el consiguiente descrédito político y militar de las Fuerzas Armadas argentinas ante el mundo y la sociedad precipitó el retiro del régimen militar y el llamado a elecciones para octubre del año siguiente, 1983 (Guber, 2004, p.14). Así como para gran parte de los habitantes del país sin vínculos con el universo castrense, para quienes pasaron por esos años por el CNBA, se trató de un verdadero hito histórico de la vida en común. Esto fue así porque en ese colegio la represión fue particularmente dura, de hecho los militares referían que gracias a su accionar ese colegio "había sido recuperado para el pueblo"10; y allí resultaron muertos y desaparecidos una proporción de alumnos mayor que la de otros establecimientos secundarios del país ${ }^{11}$. Así, el momento de la apertura política fue descripto por los egresados como "una fiesta"; "un relato de corte generacional"; y sobre todo, "el inicio de la politización indetenible”, politización que existió durante la dictadura pero en forma larvada (Méndez, 2013).

De hecho, un año después del golpe militar, en 1977, se fundó una revista que primero se llamó “La voz de la popu” y luego, en un gesto de parodia hacia el rector que en un acto los llamó de ese modo, Aristócratas del Saber. El rector pudo haber sido tanto Aníbal Rómulo Maniglia ${ }^{12}$ como Edgardo Micillo, aunque no hay acuerdo sobre este punto ${ }^{13}$. El rector y los vicerrectores tomaban una entrevista a los preingresantes. Era para descartar alumnos de condición muy humilde. Esa entrevista guardaba relación, según distintos exalumnos, con el proyecto de Maniglia de crear una nueva elite con los egresados del CNBA. Maniglia desalentó a los hijos de las familias con fortuna, ligadas visiblemente a la vida cultural de nuestra sociedad, o las que antes del golpe de Estado habían tenido poder institucional. En su lugar propició, vía la entrevista previa al examen, el ingreso de “pibes de barrio", para ellos, una forma de ascen-

10. Ese era, al menos el texto de un spot publicitario de la dictadura.

11. Como he conversado con algunos egresados, el número es difícil de determinar, dado que, si bien hubieron adolescentes que fueron muertos o secuestrados siendo alumnos del CNBA, también existe el caso de personas que fueron asesinadas siendo ya egresadas, o bien, habiendo cursado algunos años, abandonaron los estudios secundarios en algunos casos por las demandas de la misma actividad militante, y fueron muertos por la represión en esas circunstancias,

12. Maniglia se hizo cargo del rectorado cuando el cirujano Oscar Ivanissevich fue elegido ministro de Educación por segunda vez, durante el gobierno de Isabel Perón (1974).

13. No había marcadas diferencias ideológicas entre ambos, aunque sí en cuanto a la curiosidad y a la ambición intelectual, que era mayor en el primero. 
so social o de acceso gratuito a una educación de calidad; para este agente estatal, un mecanismo para poner en marcha, como dijo un egresado, "una nueva factoría".

Dos estudiantes de ese colegio cuyo signo elitista Maniglia quiso reconvertir según sus propios parámetros, fueron quienes clandestinamente fundaron esa revista que en su nuevo título recuperaba, como pregunta en clave sarcástica, la definición del rector. Con el tiempo, en el plano de la oralidad se fue horadando la entonación interrogativa y la pregunta ¿Aristócratas del Saber? se tornó una afirmación. Los fundadores de esa publicación artesanal fueron quienes iniciaron políticamente a los que vivieron la apertura política desde los claustros del Colegio, que continuaron con la publicación (con sumo sigilo durante la dictadura y abiertamente, ya en democracia), entre quienes se encontraban los cuatro egresados a los que me refiero en estas páginas.

Como resultado de esos comicios de 1983, resultó electo el Dr. Alfonsín, candidato de la Unión Cívica Radical. El rectorado de la Universidad de Buenos Aires, también en manos radicales, encaró una serie de medidas para transformar la UBA. Entre ellas, en 1984, comenzó a dar forma al proyecto del Ciclo Básico Común obligatorio para todos los alumnos que ingresaran a la universidad, iniciativa que se implementó a partir de 1985 . De ese modo, el examen de ingreso a la UBA vigente hasta entonces fue dejado sin efecto como parte de una avanzada democratizadora que contó con un amplio consenso social. Como consecuencia no prevista, los alumnos del CNBA perdieron, producto de esa medida igualadora, la prerrogativa del ingreso directo a la alta casa de estudios: una atribución compartida con otros dos establecimientos universitarios capitalinos ya mencionados, que los distinguía del resto de las instituciones de educación secundaria de Buenos Aires. En respuesta, las agrupaciones políticas organizaron huelgas, asambleas y marchas multitudinarias al rectorado, protestas que contaron con un gran poder de convocatoria, como da cuenta la participación de todas las agrupaciones estudiantiles que llenaron el Aula Magna del Colegio con ese propósito: comunistas, socialistas, radicales, peronistas, intransigentes, socialistas; y no militantes, y en cada categoría, según corresponda, independientes y orgánicos; y según el caso, católicos (de izquierda y de derecha) y laicos. Esas medidas no tuvieron demasiada repercusión en la sociedad en general.

Quien primero me habló de esos episodios fue un amigo, egresado del CNBA y doctor en Ciencias Sociales por una universidad española. Lo conozco hace más de veinte años y siempre fue un activo militante de partidos independientes de izquierda, tanto en el Colegio como en la facultad. Me reveló con cierto sonrojo la actitud que él y sus compañeros tuvieron hacia fines de 1985 . 
Meses después, le pregunté por esas marchas al historiador ya mencionado, ex dirigente del Partido Comunista, promoción 1985. Él analizó autocríticamente la respuesta del alumnado del CNBA a la iniciativa del rectorado, un gesto complejo, por el hecho de que entre quienes se estaban oponiendo a una norma de cumplimiento general había militantes de izquierda que sinceramente luchaban contra "las marcas de clase". ("Clase" en un sentido que intercambiaba la idea de "estamento favorecido" con la de "elite": un segmento en el que se concentran recursos culturales, políticos o económicos altamente deseables.) Lo que justificaba la oposición eran razones propias del juego político: “Fueron las movilizaciones más grandes - me dijo-, cuando perdemos esa prerrogativa, perdemos el último privilegio que todos los militantes defendíamos a ultranza, ya sea por convencimiento, ya sea como una excusa para actuar políticamente. Fue vivido como una inmensa derrota"14. Esas medidas de protesta supusieron un enfrentamiento con el entonces rector del Colegio: “[Horacio] Sanguinetti en septiembre de 1985 nos cerró las puertas del Colegio" [lo que implicó que las clases terminaran antes]. La derrota tenía que ver con haber perdido algo que consideraban "un derecho adquirido": la posibilidad de ingresar sin examen a la universidad, y quizás también con que la nueva modalidad de acceso - el Ciclo Básico Común, a todas luces menos exigente que un examen como los que tomaba la universidad - los haya igualado a los egresados del resto de los colegios secundarios del país. La consecuente masividad de la UBA terminaría por depreciar ese título universitario cuya posesión había sido hasta entonces una consecuencia lógica del paso por ese Colegio.

Dos exalumnos - uno de ellos, también amigo mío - fueron los únicos que votaron en contra en las multitudinarias asambleas estudiantiles. El motivo: que pensaban que "si el CBC era para todos, había que hacerlo como todo el mundo". Les sorprendía que incluso los peronistas, personas que se presentan habitualmente como antielitistas, se preguntaran “¿cómo nosotros vamos a hacer el CBC?”. Justamente, a los dos que estaban en franca minoría les resultaba curiosa la actitud segregativa de aquellos que "querían un mundo igual pero que no me lo apliquen a mí".

Un abogado que militó en Franja Morada, la agrupación estudiantil que representaba a los radicales, la fuerza oficialista a nivel nacional, apeló por un lado, a razones que tenían que ver con el cumplimiento de una acuerdo que redundaba en un "derecho adquirido", y por el otro, a cuestiones personales de índole económica, para justificar la

14. Entrevista, diciembre de 2007. 
oposición a una medida llevada adelante por el rectorado de la universidad y avalada por el del Colegio (ambos en manos de sus correligionarios):

Cuando entramos en el 81 nosotros teníamos garantizado que no íbamos a tener que dar examen para entrar a la universidad, ese era el gran beneficio que tenían tanto el Buenos Aires como el Pellegrini ... porque en el contexto de la época entrar a la universidad era complicado, sobre todo para quienes venimos de una familia de clase media que se sostenía con mucha dificultad, que te vengan cuando ya estás terminando el colegio a cambiar las reglas de juego era bastante complicado ${ }^{15}$.

4. El interés de los recuerdos referidos radica en el hallazgo de un punto común entre personas que representaban en el ámbito nacional a todas las fuerzas políticas democráticas de la Argentina, algunas abiertamente opuestas y que, empero, se encontraron unidas en tanto alumnos de un colegio centenario, en la defensa de un "derecho adquirido" que en la práctica funcionaba como un privilegio; una "diferencia" respecto del resto de los aspirantes a ingresar a la UBA que poseía "un alto grado de deseabilidad colectiva”, es decir, una "desigualdad” (Lahire, 2008). Este sentido fue corroborado por las palabras de una persona de mi confianza que se asumió como uno de los dos alumnos que se opusieron a la medida. (De todos modos, esa actitud me fue explicada con las razones que una persona de cuarenta y cuatro años ${ }^{16}$ y con una amplia trayectoria académica puede elaborar. Más allá de su efectiva negativa en aquellas votaciones, su argumentación responde tanto a esa "verdad" empírica como a la oportunidad dada, en el presente de su enunciación, de reforzar su imagen antielitista ante mí, que estaba llevando a cabo una investigación doctoral sobre la meritocracia en un colegio público.)

Pero quisiera detenerme en el gesto singular de cuatro personas, bien conceptuadas en su vida profesional, egresados del colegio público más respetado de Buenos Aires y que no tenían entonces un trato cotidiano entre sí, que en dos casos le confesaron a una amiga y en dos, a una desconocida, un hecho del que no se sentían en absoluto orgullosos, y al que en todo caso, hubieran preferido olvidar. Al margen de los reparos que presentaré a continuación, esa actitud supone un sinceramiento, y por ende una suerte de cercanía con quien en ese momento se es-

15. Entrevista, mayo del 2008.

16. En el momento de esa charla. taba desempeñando como investigadora y posible escritora de una tesis o incluso un libro sobre ellos. 
A propósito de los momentos “en que típicamente se vuelve manifiesto en el curso del trabajo de campo un espacio de intimidad social y el más puro sentido de la palabra" (Herzfeld, 1997, p.3): aquello que produce "embarazo" o, como en la experiencia referida, conduce a la expresión de justificaciones, Michael Herzfeld escribió sobre ciertas instancias que son constitutivas de "una sociabilidad común". "Vergüenza, triste autorreconocimiento... esas son los marcadores claves de intimidad cultural. No son sólo sentimientos personales, describen la representación colectiva de la intimidad” (Herzfeld, 1997, p.5). Esas confidencias “domésticas”, que se deslizan en el contexto de una charla con personas que pueden ser solo "informantes" o mucho más que eso, son implícitos que aseguran un sentimiento de pertenencia compartida de cara a los otros: la "intimidad cultural”. No se trata de volver sobre una oposición estéril entre lo local y lo global. La "intimidad cultural” no es sinónimo de un microuniverso cerrado en sí mismo. A la inversa, se despliega bajo el régimen de la disemia. Los lingüistas designan bajo el concepto de la disglosia la capacidad de los miembros de un grupo de expresarse igualmente bien en la lengua dominante como en un registro vernáculo. Ese binarismo permite pensar en un continum semántico que incluye el lenguaje y los otros sistemas de signos (Abélès, 1998, p.270).

En términos de esa ambivalencia, es posible pensar prácticas como, en primer lugar, las marchas multitudinarias contra la pérdida de la prerrogativa del ingreso directo a la UBA, en segundo lugar, la actitud del rector, y en tercero, el gesto del egresado que recomendaba a antiguos cuadros políticos que yo los entrevistase, y me sugería a mí ciertas lecturas. Quien se presentó ante mí como parte de un grupo de militantes que luchaban contra "las marcas de clase”, o quien describió su acceso al CNBA como parte de un esforzado camino que lo conduciría a la universidad, tipificando con su relato el caso de personas con recursos económicos acotados a los que el Colegio desde su fundación dio acogida, fueron los mismos que se opusieron a una medida igualadora con otros adolescentes que, igual que los alumnos del CNBA, residían en todos los barrios porteños y bonaerenses, pero no accedieron a un colegio universitario. Es verdad que esa era una posibilidad garantizada al momento de inscribirse en la institución. Pero el garante era entonces la autoridad interventora, es decir, un agente estatal de un gobierno militar. 0 sea que en el momento en que se dio a conocer la iniciativa tan rechazada por ese alumnado, pesó más atenerse a las reglas, a un pacto preexistente que los beneficiaba, que aceptar una medida igualadora que venía de la mano de la nueva autoridad política surgida con la recuperación de la democracia. 
La defensa estudiantil de su status elitista corroboraba lo mismo que mediante el sarcasmo los alumnos rechazaron: la arenga "aristócratas del saber" expresada por un agente del estado dictatorial. (Esa arenga tenía que ver con la condición elitista del alumnado del CNBA, con las prácticas de una institución que se constituyó en un primer contexto de concreción de expectativas de movilidad social para algunos alumnos provenientes de una amplia cantera nacional.) "Aristócratas del saber": una metáfora leída como desafortunada, como un insulto, fue primero apropiada mediante una torsión retórica (los signos de pregunta), y luego convalidada en la práctica enunciativa, al convertirla en afirmación.

Benedict Anderson (1993) ha encontrado en algunas imágenes literarias la referencia a un "conjunto colectivo de lectores" (p. 28) en la que se denotaba implícitamente una comunidad imaginada en embrión. Lo que el autor estaba buscando eran argumentos para sostener su idea de que la adhesión a la nación corresponde a la construcción de una comunidad imaginada. Herzberg (1997) encuentra problemáticas esas generalizaciones, ya que considera presentan "un modelo de arriba hacia abajo que convierte a lo local en un receptáculo pasivo de las corrientes dominantes, que no muestra cómo esas creencias se enraízan en la vida cotidiana de la gente” (p. 270) y que básicamente presenta a las personas como iguales entre sí.

En un momento de la historia argentina en el que la relación entre el Estado (representado por un agente de la dictadura) y la nación (encarnada en el Colegio de la Patria) fue, en palabras de Bruce Kapferer (1988), de oposición y desconfianza, la relación entre los entonces alumnos y rector parece mostrar otra versión del modelo top-down: la invención de la imagen "aristócratas del saber" muestra que previamente ese funcionario (señalado como antielitista) había sido arrasado por la "plástica modeladora del Colegio" ${ }^{17}$, por el canon moral meritocrático de la institución. Lo que posiblemente dijera la distancia irónica de los alumnos frente a su frase es que ellos no estaban dispuestos a ser definidos o hablados por él: “un milico” ${ }^{\mathbf{1 8}}$. Lo del elitismo no era la materia de discusión. De hecho es algo que les dijeron desde el primer día de clases y muchos discutieron pero con una retórica elitista. La cuestión subyacente a esa negociación por el sentido de la imagen "aristócratas del saber" parecía ser quién llevaba sobre sus hombros el peso de la tradición del centenario colegio, y en consecuencia, quién estaba llamado a garantizar

17. La frase es de otro rector: Sanguinetti.

18. Muy despectivamente, un militar. su permanencia a lo largo de los años. El tiempo mostró que, entonces, fueron ellos, no una autori- 
dad intrusa ${ }^{19}$, sino, por lo general hombres del Colegio ${ }^{20}$, como en el presente lo están comenzando a hacer algunos de sus hijos e hijas, nuevos alumnos del CNBA.

5. La intimidad cultural que puede implicar la "filtración" acerca de las marchas contra implementación del examen, permite, en su ambigüedad y al menos en términos de Hersfeld, identificar un sentimiento de pertenencia compartida con otros. Una cuestión central para pensar de qué tipo de relación social comunitaria se trata es que las protestas tuvieron un fin específico, ligado a la preservación de un “derecho adquirido". La fuerza de esa lucha estudiantil reposaba en la confluencia, en esos momentos, de una parte mayoritaria del alumnado; personas que no se unieron por haberse sentido "hermanos en el aula y en la vida" (otra imagen generalizadora que algunos repiten y muchos rechazan) ${ }^{\mathbf{2 1}}$ sino por haber logrado construir un acuerdo, que si bien fue producto de encarnizadas discusiones llevadas a cabo en asambleas multitudinarias, no pudo lograrse sin que existiera "algo" común que lo sustentara. ¿Se puede pensar, en la situación descripta, a estos egresados en términos de “comunidad"? ¿Es posible plantearlo de esa forma cuando lo que prevalece es un modo de relación social que tienen como prenda común la persecución de un fin, lo que volvería ese posicionamiento como más propio de la "sociedad", al menos según la distinción propia de la sociología clásica?

Para Ferdinand Tönnies (1979), la teoría de la sociedad construye un círculo de hombres que como en la comunidad conviven pacíficamente, pero no están esencialmente unidos sino esencialmente separados, y “mientras en la comunidad permanecen unidos a pesar de todas las separaciones, en la sociedad aparecen esencialmente separados a pesar de todas las uniones" (p. 65). Esa idea de comunidad, en mis términos, "muda" y la búsqueda de un fin racional, son elementos que Tönnies no toma juntos: “una vez que comienza a proclamar su valor único ... una comunidad que habla de sí misma ... es una comunidad que ha dejado de existir" (Bauman, 2003, p.18) ${ }^{22}$

19. El enunciado es de un ex alumno egresado en la década de 1940, es decir que no corresponde al recorte etario que realizamos para este artículo..

20. El enunciado es de un ex alumno de la década de 1950, es decir que no corresponde al recorte etario que realizamos para este artículo.

21. Un hombre egresado en los cincuenta que tuvo un alto cargo en la UBA y siguió muy de cerca la vida del CNBA hasta aproximadamente el 2005, me dijo que le disgustaba la consigna "Hermanos en el aula y en la vida" que proclamaba Sanguinetti en sus discursos y lema de la Asociación de exalumnos (aunque los egresados de épocas previas a los setenta consultados no la hayan escuchado jamás): "yo no me siento hermano de (el líder del movimiento guerrillero montonero y ex alumno del CNBA, Mario Eduardo) Firmenich", me dijo.

22. Se debe tener en cuenta que comunidad y sociedad no son necesariamente instancias sucesivas. Como sostiene Daniel Álvaro (2010, mayo), “la comunidad no siempre es algo que antecede a la sociedad: "unas veces, deseo romántico por una supuesta comunidad perdida, y otras, no menos frecuentes, por una comunidad futura, por una comunidad que se anuncia después y no antes de la sociedad". 
Pero a su vez, comunidad y sociedad no necesariamente son siempre para la sociología clásica, modos de relación estrictamente disyuntos. De hecho, Max Weber (1979) escribió en la parte nueva de Economía y Sociedad, aquella en la que aparece el Weber sociólogo, el que hace referencia a las relaciones de comunización en tanto tipos ideales ${ }^{23}$, que "la inmensa mayoría de las relaciones sociales participan en parte de la "comunidad" y en parte de la "sociedad" (p. 33). "Una relación que por su sentido normal es una comunidad - seguía Weber (1979. p. 34) - puede estar orientada por todos o parte de sus partícipes con arreglo a ciertos fines racionalmente sopesados [es decir, aquello que caracteriza a la sociedad]". Pero la comunidad

solo existe propiamente cuando sobre la base de ese sentimiento de la situación común la acción está recíprocamente referida -no bastando la acción de todos y cada uno de ellos frente a la misma circunstancia- y en la medida en que esta referencia se traduce el sentimiento de formar un todo (Weber, 1979, p. 34).

Pablo de Marinis (2010, mayo), lo explica del siguiente modo:

En la parte vieja de Economía y Sociedad, Weber maneja una noción de comunidad bastante neutral, equivalente a "grupo", luego pesará más el carácter procesual de una consideración de la vida colectiva que "deviene" comunidad o sociedad, tipos que podrán convivir en una misma configuración. Así, el foco pasará a colocarse en el posicionamiento subjetivo de los participantes de una determinada relación social, poniendo ya sea el énfasis en la sensación de "formar parte de un todo" o bien en la persecución racional de fines y ajustes de intereses (pp.18-19).

Respecto de la primera idea, la de formar parte de un todo, es posible pensar que en esa secuencia de protestas que derivó en una derrota para quienes se oponían a perder la prerrogativa de ingresar directamente a la UBA se actualizara "un pathos y un sentimiento de comunidad" propio de momentos de profundo enfrentamiento con un otro al que se percibe como amenazador. Justamente es en esos momentos en que

23. El autor se refiere al Weber sociólogo para diferenciarlo del Weber historiador, que emerge en los Ensayos sobre la religión, y el Weber, en sus términos “utópico", que aparece en los escritos sobre las comunidades políticas. Ver Pablo de Marinis (2011, enero/junio, p. 137). es amenazado el status de alguna de la partes, cuando se ponen de manifiesto los valores morales de las formaciones colectivas. Por su parte, Weber (citado por De Marinis 2011, enero/junio) 
señaló que la comunidad típico idealmente, "está impregnada de una tonalidad ética peculiar” (p. 19). De ese modo “comunidad sirve para decir quiénes somos nosotros y quiénes son ellos” (De Marinis, 2011, enero/junio, p. 129). “La tonalidad ética particular" de los egresados del CNBA estaría definida por la idea misma de meritocracia; por la desigualdad (Lahire, 2008) que instaura el esfuerzo.

Si estos egresados son parte de una comunidad más amplia ¿cómo se conjuga esa idea con la circunstancia de que el episodio referido haya ocurrido veinticinco años antes de que algunos de sus protagonistas me lo refirieran? Esa cuestión es central porque alude al problema de la persistencia de una comunidad a lo largo del tiempo. El gesto del historiador de elegir, por su propia iniciativa, egresados para que yo entrevistase, podría mostrar que aquello que los une no es sólo el pasado: la adolescencia compartida en un lugar que él mismo describió como "sublime" por el miedo que tenían. Esa iniciativa era un trabajo a favor de un colectivo que a pesar de los años transcurridos revestía, aparentemente, para ese egresado, cierta importancia, por lo que se ocupaba de elegir a los voceros que testimoniarían sobre su grupo.

Weber, en la "parte vieja" de Economía y Sociedad, es decir, en la que piensa a la comunidad como "grupo" propone algunas ideas que tomo no para aplicarlas a mi objeto de estudio, sino para sensibilizar la mirada sobre aspectos que, muchas veces, no sabemos cómo nombrar o cuán relevantes pueden resultar para el análisis de nuestros datos, como por ejemplo, la relación entre ciertas experiencias vividas colectivamente en la esfera pública y la formación de cierta afectividad común. A propósito de las comunidades lingüísticas, Weber (1979) señaló que "los sentimientos colectivos no son unívocos y pueden ser nutridos por distintas fuentes. Pueden representar un papel importante los recuerdos políticos comunes" (pp. 326-327).

La preocupación por aquello que colabora en la preservación de algunas comunidades está tempranamente en Weber. El autor se refirió en "Estamentos y clases" a "profesores que sentían la necesidad ideal de ocuparse de ciertas comunidades lingüísticas eslavas (...) [a las que] han ayudado a preservarse” (Weber, 1979, p. 17).

Cuando algunos egresados como el historiador me recomendaron lecturas, o cuando escogieron como posibles entrevistados a algunos egresados (especialmente a quien fuera un "cuadro" político), yo tenía la sensación de que me estaban "armando el campo". Sólo más tarde advertí que esa actitud, que encontré en egresados de varios momentos del Colegio, podía tener que ver con la preservación de ese grupo, por el intento de controlar la imagen pública de esta que podía surgir de mis escritos. 
Weber se refirió, también en "la parte vieja" de su texto, al problema de la preservación de los privilegios, cuestión decisiva para la teoría de las elites. Como explicó Perla Aronson (2008), “los estamentos agrupan a las personas en términos de la posesión de (o aspiración de poseer) privilegios positivos o negativos en la consideración social” (p. 9). En el apartado que titula "Estamentos y clases", Weber (1979) llama "situación estamental” "a una pretensión típicamente efectiva de privilegios positivos o negativos en la consideración social fundada en el modo de vida y por lo tanto en las maneras formales de educación o en un prestigio hereditario o profesional” (p. 245).

Más adelante, se dedica a describir la tendencia al monopolio en tanto fuerza impulsora de una comunidad económica: tendencia que se dirige contra otros competidores que se distinguen por caracteres comunes, positivos o negativos. Su finalidad está en cerrar en alguna medida a los de afuera las probabilidades (sociales y económicas) en juego (Weber, 1979, p. 276). En la conservación de privilegios por parte de una comunidad estamental también está en juego su continuidad a través del tiempo, cuestión que nos devuelve al problema de las marchas contra el examen generalizado para ingresar directamente a la UBA. Un derecho adquirido.

\section{Palabras finales}

Hasta aquí, un intento de examinar maneras posibles de categorizar la actividad individual y colectiva de un grupo que a veces utiliza modos no codificados por la sociología para asegurar su continuidad a lo largo del tiempo. Esos modos pueden ser parte de una dinámica propia de algunas elites en la que opera el reconocimiento mutuo entre personas con una experiencia formativa común, y, a la vez, la diferenciación con quienes no vivieron ese tipo de socialización. El funcionamiento de retóricas, imágenes y repertorios que relevamos en estas páginas, que no nos pareció disociado de dichos modos de sostener la permanencia, resultó a nuestros ojos atravesado por una marcada tensión entre el elitismo propio de quienes aspiran a acceder a posiciones de preeminencia en la escena nacional, y la idea republicana de igualdad de derechos, propia de una institución abierta a personas de distintos orígenes sociales.

Por lo mismo apareció la posibilidad de reflexionar sobre los momentos en que, producto de la imposibilidad, por parte de los actores, de salir airosamente de esa tensión, quedó al descubierto un lenguaje vernáculo, confidencial, que sólo se pronuncia "de entre casa", en el que creímos encontrar algo tangible que remita a un 
sentimiento de pertenencia compartida de cara a otro, esto es, al menos en teoría, a la existencia de una comunidad.

Esos “otros" resultamos ser nosotros mismos, los investigadores, que somos lo más asequible que tenemos a mano cuando se trata de examinar una relación social tan esquiva, y no es descabellado sospechar que podamos estar funcionando con nuestro análisis como agentes mismos del convencimiento de lo que queremos probar: la existencia de una comunidad. ${ }^{24}$

Así, quienes estudiamos las elites, estamos trabajando también para que esos grupos adquieran una forma perdurable para sostenerse en el tiempo, dado que al fin y al cabo serán nuestro objeto de estudio mientras mantengan su condición de elites, aunque esa persistencia en las alturas suponga para ellos la necesidad de encontrar exégetas y voceros. De este modo, los cientistas sociales encarnamos una forma compleja de subordinación en la que somos a la vez parte subalterna e interesada. 


\section{Referências bibliográficas}

Abélès, M. (1998). M. Herzfeld, Cultural intimacy. Social poetics in the nation states. L'Homme, 38(145), 269-272.

Álvaro, D. (2010, mayo). Los conceptos de “comunidad” y “sociedad”. In F. Tönnies, Papeles del CEIC, 1(58), 1-24.

Anderson, B. (1993). Comunidades imaginadas. México: Fondo de Cultura Económica.

Aronson, P. (2008, noviembre). La visión weberiana del conflicto social. Conflicto Social, $1(0), 8-24$.

Bauman, Z. (2003). Comunidad. En busca de seguridad en un mundo hostil. Buenos Aires: Siglo Veintiuno.

De Marinis, P. (2010, mayo). La comunidad según Max Weber: desde el tipo ideal de la Vergemeinschaftung hasta la comunidad de los combatientes. Papeles del CEIC, 1(58), 1-36.

De Marinis, P. (2011, enero/junio). La teoría sociológica y la comunidad. Clásicos y contemporáneos tras la huella de la "buena sociedad”. Entramados y perspectivas, Revista de la Carrera de Sociología, 1(1), 347-382.

Di Piero, M. E. (2013, 29 y 30 de octubre). Tensiones entre la inclusión y la selección en la escuela media: el caso de un grupo de instituciones tradicionales en la ciudad de La Plata. $2^{a}$ Reunión Internacional sobre formación de las elites, Núcleo de estudios sobre Elites y Desigualdades Socioeducativas (NEEDS-FLACSO), Buenos Aires.

Guber, R. (2004). De chicos a veteranos. Memorias argentinas de la guerra de Malvinas. Buenos Aires: Editorial Antropofagia.

Herzfeld, M. (1997). Cultual intimacy. Social poetics en the nation-state. New York: Routledge.

Kapferer, B. (1988). Legends of people, Myths of state. violence, intolerance, and political culture en Sri Lanka and Australia. Washington and London: Smithsonian Institution Press.

Lahire, B. (2008). "Cultura escolar, desigualdades culturales y reproducción social. In: E. Tenti Fanfani, Nuevos temas en la agenda política educativa. Buenos Aires: Siglo XXI.

Latour, B. (2008). Reensamblar lo social. Una introducción a la teoría del actor-red. Buenos Aires: Manantial.

Méndez, A. (2013). El Colegio. La formación de una elite meritocrática en el Nacional Buenos Aires. Buenos Aires: Sudamericana. 
Noel, G. D. (2014, mayo). Las dimensiones morales de la vida colectiva: exploraciones desde los estudios sociales de las moralidades. Papeles de Trabajo, 14 14-32.

Southwell, M. (2011). La educación secundaria en Argentina. Notas sobre la historia de un formato. In G. Tiramonti, Variaciones sobre la forma escolar. Límites y posibilidades de la escuela media. Rosario: Homo Sapiens.

Tiramonti, G. (2004). La configuración fragmentada del Sistema Educativo Argentino. Cuadernos de Pedagogía, 12, 33-46. Rosario: Libros del Zorzal.

Tönnies, F. (1979) Comunidad y asociación, Barcelona: Península.

Weber, M. (1979). Economía y sociedad. México D.F.: Fondo de Cultura Económica.

Ziegler, S. (2004). La escolarización de las elites: un acercamiento a la socialización de los jóvenes de sectores favorecidos en la Argentina actual. In G. Tiramonti (Comp.), La trama de la desigualdad educativa. Mutaciones recientes de la escuela media. Buenos Aires: Manantiales.

Zimmermann, E. (1995). Los liberales reformistas. Buenos Aires. Editorial Sudamericana y Universidad de San Andrés.

Submetido à avaliação em 21 de setembro de 2014; aceito para publicação em 10 de fevereiro de 2015. 